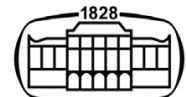

AKADÉMIAI KIADÓ

Acta Chromatographica

33 (2021) 2, 162-169

DOI:

$10.1556 / 1326.2020 .00774$

(c) 2020 The Authors

ORIGINAL RESEARCH

PAPER

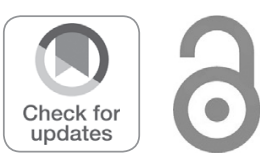

\section{Development and validation of HPLC-UV method for the quantitative analysis of carcinogenic organic impurities and its isomers in the sodium polystyrene sulfonate polymer}

\author{
PUSHPAVATI ZINJAD, PRIYANKA GONDHALE, \\ SHRIKANT KULKARNI, BHASKAR MUSMADE, \\ SHRINIVAS BHOPE* (1) and SRIRAM PADMANABHAN
}

Sava Healthcare Limited, Research Centre (ADL Dept), Block D1, Plot No. 17/6, MIDC, Chinchwad, Pune, 411019, India

Received: March 06, 2020 • Accepted: April 07, 2020

Published online: June 1, 2020

\begin{abstract}
Sodium polystyrene sulfonate (SPS) powder is in use for over 50 years for the treatment of hyperkalemia. SPS powder is official in United States Pharmacopoeia, British Pharmacopoeia and European Pharmacopoeia. However, till date, no study has been published on the assessment of organic impurities for this drug. The organic impurities in bulk drug and finished product are associated with their safety, efficacy and stability. A simple, rapid, specific, precise and an accurate HPLC method has been developed for the estimation of toxic organic impurities like styrene, naphthalene, divinyl benzene (DVB) and ethylvinyl benzene (EVB) from SPS bulk drug and finished product. The developed method was validated for specificity, accuracy, precision, linearity, limit of detection (LOD), limit of quantitation (LOQ), solution stability, ruggedness and robustness. The influence of acid, alkali, oxidative stress, photolytic stress, thermal stress and humidity stress conditions on SPS bulk powder and finished product has been studied and reported. The proposed method can be successfully employed for the impurity testing of commercial batches of the bulk drug and finished products of both sodium salt and calcium salt of polystyrene sulfonate.
\end{abstract}

\section{KEYWORDS}

bulk drug, finished product, HPLC, related substances, sodium polystyrene sulfonate

\section{INTRODUCTION}

Polystyrene sulfonates are polymers derived from polystyrene by the addition of sulfonate functional groups. They are widely used as ion-exchange resins to remove ions such as potassium, calcium and sodium from solutions in technical or medical applications [1]. These polymers are usually supplied as either sodium or calcium form. In medicine, it is used as a potassium binder for treating acute and chronic kidney disease in people with hyperkalaemia (abnormal high blood serum potassium levels) [2]. Sodium polystyrene sulfonate (SPS) is the sodium salt of sulfonated styrene copolymer with divinylbenzene. This being a cation-exchange resin, exchanges sodium ions for potassium ions and other cations in the gastrointestinal tract when given orally or rectally [2]. The exchanged resin is then excreted in the faeces. It is used to enhance potassium excretion in the treatment of hyperkalaemia, associated with anuria or severe oliguria. Although it is official in USP, BP and EP, the related substance method is not available in any of these official monographs.

Several researchers in the past [3-5] have indicated that commercial samples of SPS could contain ionic impurities at levels that may be a significant concern for human health. The
*Corresponding author.

E-mail: shrinivas.bhope@savaresearch. com 
possible impurities include surface-active agents [3] or inorganic salts such as $\mathrm{Na}_{2} \mathrm{SO}_{4}$ [5]. The presence of these impurities has a strong effect on the polyelectrolyte properties like viscosity [4, 6-11], osmotic coefficiency [12-15], surface tension [16-19], etc.

From the drug point of view, the impurity, even in small amounts, is important with respect to the safety, efficacy and stability of pharmaceutical products. From the bulk drug specification; we have found four known impurities as listed in Fig. 1 for this active pharmaceutical ingredient (API) viz. styrene, naphthalene, divinyl benzene (DVB) and ethylvinyl benzene (EVB). Styrene is primarily used in the production of polystyrene plastics and resins. It is also used as an intermediate in the synthesis of materials used for ion exchange resins and to produce copolymers [20]. Styrene is regarded as a 'known carcinogen', especially in case of eye contact but also in case of skin contact, of ingestion and inhalation, according to several sources [21-23]. Chronic exposure to styrene in humans results in effects on the CNS, with symptoms such as headache, fatigue, weakness, depression, CNS dysfunction (reaction time, memory, vasomotor speed and accuracy, intellectual function) and hearing loss, peripheral neuropathy, minor effects on some kidney enzyme functions and on the blood [24-26]. Divinyl benzene is a crosslinking monomer used primarily for copolymerization with styrene to produce ion-exchange resins [27, 28]. The bifunctionality conferred by the two vinyl groups makes divinyl benzene a highly reactive crosslinking agent and may also contribute to its toxicity. Naphthalene is a bicyclic aromatic hydrocarbon used as an intermediate in the production of phthalic anhydride. Phthalic anhydride is used in the manufacture of ion exchange resins.

To the best of our knowledge, there are no reports on methods for quantitation of organic impurities for this bulk drug. Hence, an urgent need to develop a simple, rapid and stability-indicating method for the same was envisaged and the results are disclosed in this paper.

In order to improve the quality control of related substances for this bulk drug and its finished product, the whole analytical process was optimized from sample preparation to chromatographic separation. A sensitive and reliable HPLC-UV method was developed and validated for the quantitation of related substances. The present study provided new information and supporting data for the overall quality control of the SPS bulk powder and finished dosage form.

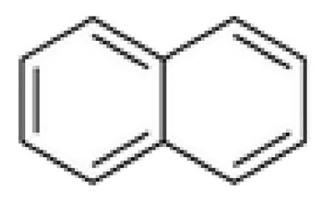

[a!

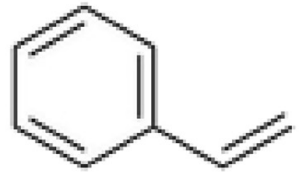

ty

\section{EXPERIMENTAL}

\section{Reagents and materials}

SPS bulk drug, impurity standards viz. styrene; divinyl benzene, and naphthalene were provided by Ion Exchange (India) Ltd, (Ankleshwar, Gujarat, India). HPLC-grade acetonitrile (Fisher Scientific, USA) and water (Merck Millipore, USA) was used as mobile phase (50:50). Acetone HPLC grade (Fisher, Scientific, USA) was used as a diluent. All other chemicals and reagents were of analytical grade, unless otherwise mentioned.

\section{Instrumentation}

The analysis was carried out using a Shimadzu (LC 2010C HT) system (Shimadzu Corporation, Kyoto, Japan). The HPLC instrument consisted of a binary pump, an online degasser, an auto-sampler, a thermostatically controlled column compartment and a photo diode array detector (SPD-MZOA). The data were collected and processed using Lab Solution ${ }^{\mathrm{TM}}$ software from Shimadzu. RP HPLC method was used for the quantification of all impurities.

\section{Chromatographic conditions}

The chromatographic separation was achieved on an SUPLEX PKB-100, $5 \mu \mathrm{m}, 250 \mathrm{~mm} \times 4.6 \mathrm{~mm}$ (Daicel, USA) column. The temperature of the column and the autosampler was maintained at $25{ }^{\circ} \mathrm{C}$ and $15{ }^{\circ} \mathrm{C}$, respectively. Analysis was completed on isocratic mode for $45 \mathrm{~min}$. An HPLC grade acetonitrile (A) and water (B) with the ratio of 50:50 was used as mobile phase. The injected sample volume

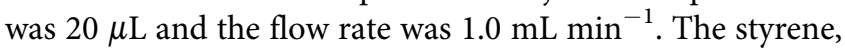
divinyl benzene isomers and ethylvinyl benzene isomers were detected at $254 \mathrm{~nm}$ and naphthalene was detected at $220 \mathrm{~nm}$.

\section{Preparation of standard solutions}

1,000 ppm each of styrene, naphthalene and divinyl benzene was prepared in acetone and further diluted to get $1 \mathrm{ppm}$ of each impurity prior to injection into the HPLC columns.

\section{Preparation of sample solution}

100,000 ppm of SPS sample solution was prepared in $100 \%$ HPLC grade acetone and centrifuged at $5000 \mathrm{rpm}$.

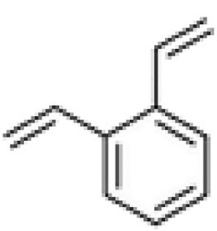

[e]

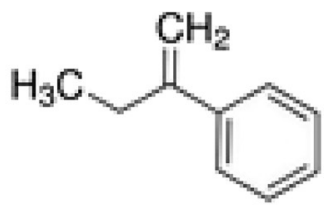

[a]

Fig. 1. [a]: Chemical structure of naphthalene. [b]: Chemical structure of styrene. [c]: Chemical structure of divinyl benzene. [d]: Chemical structure of ethylvinyl benzene 


\section{Procedure}

Equal volumes of diluent, standard solution and sample solution were injected into the chromatograph. The styrene, naphthalene, divinyl benzene with meta- and para-isomer and ethylvinyl benzene peaks were identified by comparing the sample chromatogram with the impurity standard chromatograms. The chromatogram was run in dual channel, channel 1: $\lambda 220 \mathrm{~nm}$ for naphthalene and channel $2: \lambda$ $254 \mathrm{~nm}$ for styrene, divinyl benzene, ethylvinyl benzene and unknown impurities.

\section{Method validation}

The developed HPLC method was validated according to International Conference on Harmonization ( $\mathrm{ICH}$ ) guidelines [29] to demonstrate suitability for the intended purpose. System suitability, selectivity, accuracy, precision, linearity, range, limit of detection (LOD), limit of quantitation (LOQ) and robustness were evaluated.

System suitability parameters were measured so as to verify the system, method and column performance. The selectivity of the method was studied by comparing the test sample solution and the forced degradation solution to evaluate the resolution of the analyte from other interfering components. To establish the linearity and range, at least five concentration levels for each analyte were diluted. Linearity was described by regression line equation and its correlation coefficient. The LOD and LOQ were defined as the concentration of the analyte with a signal-to-noise ratio of 3:1 and 10:1, respectively. The precision was a measure of reproducibility of the analytical method and determined by preparation and measurement of further six samples. Recovery experiments were carried out by the standard spiked technique. Three different concentration levels (LOQ, 50\%, $100 \%$ and $150 \%$ ) of impurity reference standards were spiked to the pre-analysed placebo samples in triplicate. Robustness was studied by making small variations in flow rate $\left(1.0 \pm 0.2 \mathrm{~mL} \mathrm{~min}^{-1}\right)$, column oven temperature $(25 \pm$ $5{ }^{\circ} \mathrm{C}$ ) and mobile phase composition ( $\pm 5 \%$ organic phase) to evaluate the methods' capacity to remain unaffected. The system suitability parameters like resolution, tailing factor and theoretical plates were monitored throughout the validation study.

\section{LOD and LOQ determination}

A series of low concentrations from 0.01 to $0.50 \mathrm{ppm}$ of styrene, naphthalene and divinyl benzene were prepared based on standard response and injected in triplicate. The calibration curves were prepared for area vs. concentration for styrene, naphthalene, divinyl benzene and ethylvinyl benzene isomers (meta-DVB \& para-DVB and meta-EVB \& para-EVB). From the calibration curves, intercept and slope were determined and the LOD and LOQ were calculated.

\section{Linearity and range}

The linearity of method for the analysis of styrene, naphthalene, meta-DVB \& para-DVB and meta-EVB \& para-
EVB was demonstrated by preparing solutions over the concentration level ranging from LOQ to $150 \%$ of target concentration (1 ppm). The correlation coefficient between concentration \& peak area and $y$-intercept of the correlation plot was evaluated.

\section{Precision}

The precision of an analytical procedure express the closeness of agreement between a series of measurement obtained from multiple sampling of the same homogeneous sample under the prescribed conditions.

\section{System precision}

Standard solution was prepared as described in analytical method and injected in six replicates.

\section{Method precision}

For this study, six samples were prepared by spiking all specified impurities at specification level as per the analytical method described. The \% impurities of these spiked samples were determined and the precision of the method was evaluated by computing the \% RSD of the results.

\section{Ruggedness}

The ruggedness of the method was demonstrated by carrying out precision study in six replicates of a single batch impurity spiked sample by different analysts, on different days on different instruments.

\section{Accuracy (recovery)}

The accuracy of an analytical procedure expresses the closeness of agreement between the value which is accepted either as a conventional true value or as an accepted reference value and the value obtained by the method. Impurity standard solutions were spiked in sample powder at different concentration levels from LOQ level, 50\%, 100\% and 150\% of target concentration (1 ppm) and analysed as per the method. The \% recovery was calculated for all the above mentioned levels.

\section{Degradation study}

The forced degradation study was carried out to demonstrate specificity of stability indicating method and get an insight into degradation pathways and degradation products of the drug substance and drug product. During this study, the drug substance was exposed to various stress conditions like $1 \mathrm{M} \mathrm{HCl}$ for $24 \mathrm{~h}, 1 \mathrm{~N} \mathrm{NaOH}$ for $24 \mathrm{~h}, 75 \%$ humidity for 7 days, $3 \%$ hydrogen peroxide for $24 \mathrm{~h}$, UV Visible light (1.2 million lux hours) for $24 \mathrm{~h}$ and heat $\left(60^{\circ} \mathrm{C}\right)$ for $24 \mathrm{~h}$. 


\section{RESULTS AND DISCUSSION}

\section{Optimization of the method}

The polymeric impurities of SPS molecule were difficult to get analysed on the HPLC. In order to achieve better detection, the HPLC conditions were optimized. A series of mobile phases with varying compositions of different organic modifiers were tested. Acetonitrile was chosen as the organic portion of the mobile phase because of lower background noise and strong elution effect on targeted impurities to shorten the analysis time, in comparison with methanol. Blank acetonitrile did not interfere with the determination of related substances. Since the octadecyl silane (C18) column has more hydrophobic properties than C8 column, whose bonding reactions with the polymeric impurities (long chain alkane) were stronger than the octyl silane phase for column packing. Different columns with packing materials, like Waters Symmetry C18, Agilent Zorbax SB C18, YMC triart C18, Inertsil ODS 3V, were tested. However, a complete resolution of all the known impurities was achieved with Suplex pkb-100 column (250 $\times 4.6 \mathrm{~mm}, 5 \mu \mathrm{m}$ ). This column gave a better resolution with steady baseline for all impurity peaks. Divinyl benzene (DVB) showed two peaks as meta-divinyl benzene and paradivinyl benzene. Ethylvinyl benzene (EVB) is an isomer of divinyl benzene having two peaks as meta-ethylvinyl benzene (meta-EVB) and para-ethylvinyl benzene (para-EVB). The impurity standard solution chromatogram for naphthalene at $220 \mathrm{~nm}$, impurity standard chromatogram for styrene, divinyl benzene isomers and ethylvinyl benzene

a

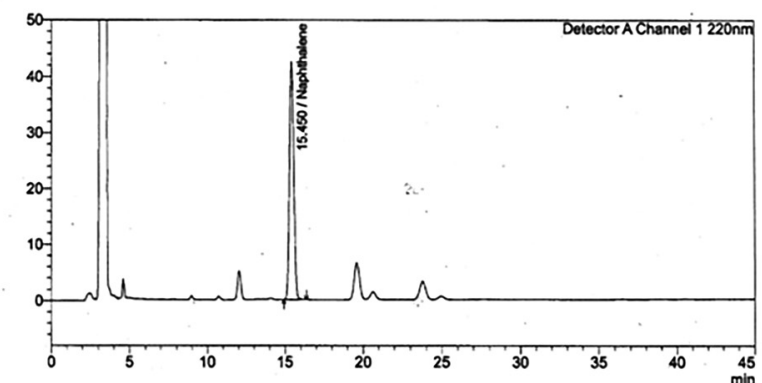

$c_{m /}$

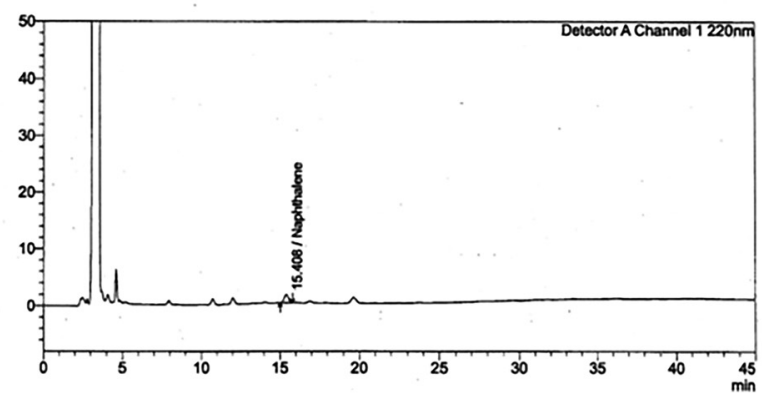

isomers at $254 \mathrm{~nm}$, sample solution chromatogram for naphthalene at $220 \mathrm{~nm}$, sample solution chromatogram for styrene, divinyl benzene, ethylvinyl benzene and unspecified impurities at $254 \mathrm{~nm}$ are listed in Fig. 2.

We tried different diluents like methanol, acetonitrile and acetone for the efficient extraction of the impurities. Acetone was found to be the most suitable. The filter interference study was performed by filtering the sample and standard solutions through conventional $0.45 \mu \mathrm{m}$ Nylon and polyvinylidene difluoride (PVDF) and it was compared with the sample centrifuged at 5,000 rpm. In both Nylon and PVDF filters, all the impurities were getting adsorbed.

The surface tension study revealed that, both the marketed sample (Kayexalate) and Sava sample have shown comparable surface tension values at various concentrations indicating the comparable surface activity of both the samples.

\section{Validation study}

In this study, system suitability, selectivity, accuracy, precision, linearity, range, LOQ, LOD and robustness were evaluated for the validated HPLC method. The system suitability test was determined by six replicate injections of the standard preparation. The relative standard deviation (RSD) of each compound's peak area and retention time was less than $1.0 \%$, peak resolution was greater than 1.5 and theoretical plates were at least 3,000 for each peak. The tailing factor was in the range of $0.9-1.1$. The results indicated that the system was suitable for all the peaks. The outcome of selectivity demonstrated that all the peaks

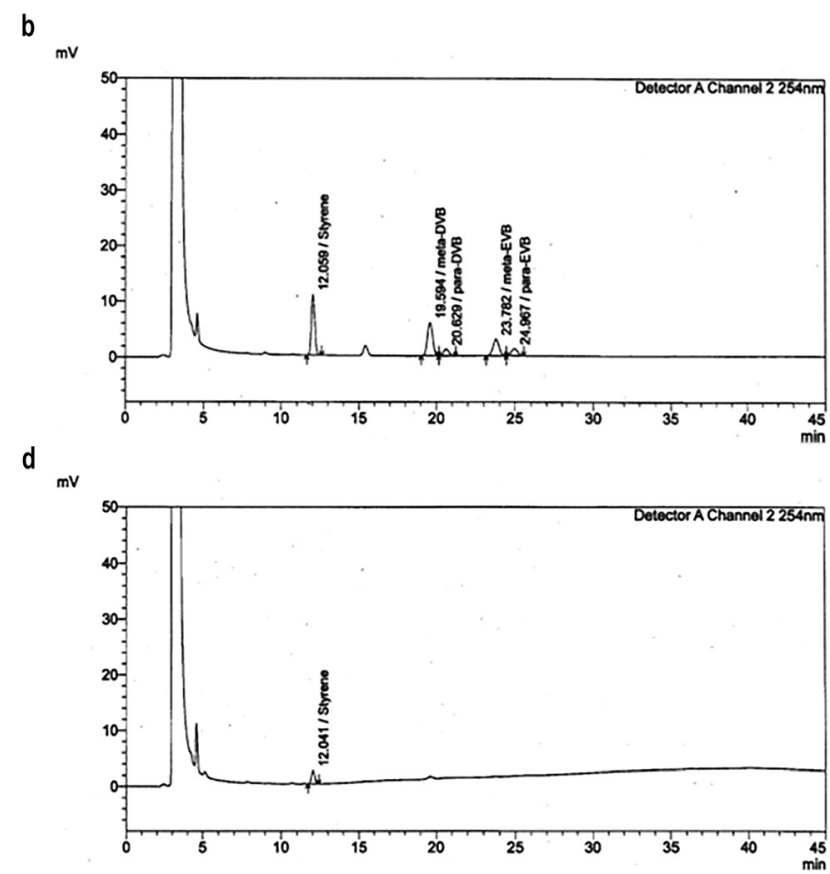

Fig. 2. [a]: Impurity standard chromatogram for naphthalene at $220 \mathrm{~nm}$. [b]: Impurity standard chromatogram for styrene, divinyl benzene isomers and ethylvinyl benzene isomers at $254 \mathrm{~nm}$. [c]: Sample solution chromatogram for naphthalene at $220 \mathrm{~nm}$. [d]: Sample solution chromatogram for styrene, divinyl benzene, ethylvinyl benzene and unspecified impurities at $254 \mathrm{~nm}$ 

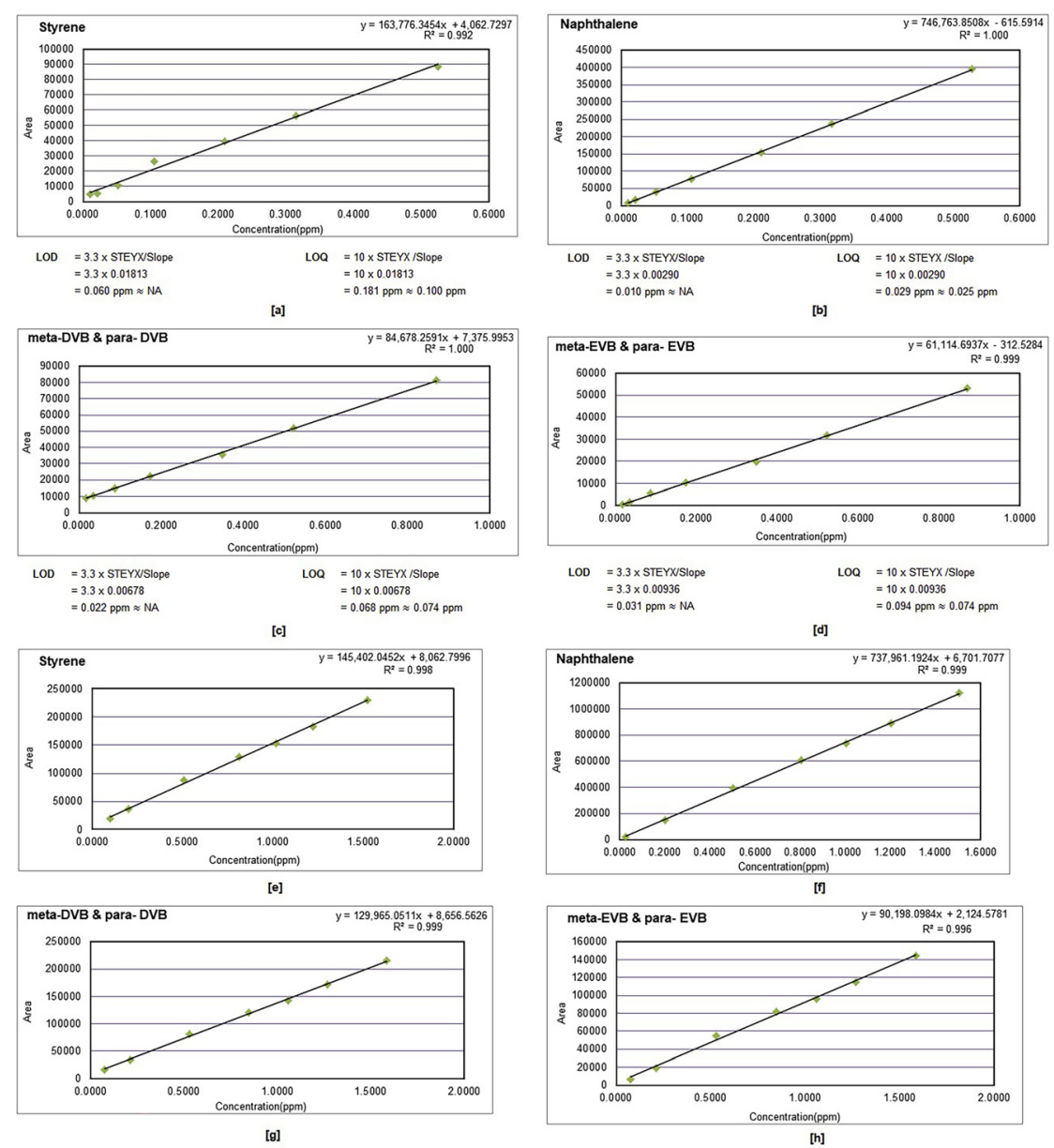

Fig. 3. [a]: LOD, LOQ graph for styrene. [b]: LOD, LOQ graph for naphthalene. [c]: LOD, LOQ graph for meta-DVB \& para-DVB. [d]: LOD, LOQ graph for meta-EVB \& para EVB. [e]: Linearity graph for styrene. [f]: Linearity graph for naphthalene. [g]: Linearity graph for meta-DVB \& para-DVB. [h]: Linearity graph for meta-EVB \& para-EVB

were baseline separated without any interference. During the forced degradation study it was observed that, there was a significant increase in total impurities without any degradation in the sodium content of the degraded samples (Table 1). Mass balance is normally analysed, if a drug product degrades under certain conditions, to form degradant products partially or completely. The analysis of degraded products with respect to the original product is to be made to understand the extent of degradation. With regard to our product, it is a DVB-cross linked sulfonated polystyrene resin. Due to cross-linking, this polymer is insoluble in water and organic solvents. It is not much affected by acid or alkali. We conducted degradation study in UV light, oxidizing medium, acidic medium, alkaline medium and high temperature. The product was analysed for $\mathrm{Na}$ content by Flame photometry and related substances by HPLC after subjecting to various forced degradation conditions. Slight increase in the isomers of both divinyl benzene and ethylvinyl benzene is observed in most of the degraded samples during

Table 1. Impurities for untreated and treated samples in $\mathrm{ppm}$

\begin{tabular}{lccccc}
\hline Stress condition & Naphthalene & Styrene & $\begin{array}{c}\text { Meta- \& } \\
\text { para-DVB }\end{array}$ & $\begin{array}{c}\text { Meta- \& } \\
\text { para-EVB }\end{array}$ & $\begin{array}{c}\text { Any individual } \\
\text { unspecified }\end{array}$ \\
\hline Untreated sample & 0.066 & 0.207 & ND & ND & ND \\
Thermal & 0.183 & 0.189 & 0.390 & 0.232 & 0.138 \\
Photolytic & 0.073 & 0.245 & 0.452 & 0.319 & 0.141 \\
Humidity & 0.312 & 0.581 & 0.419 & 0.242 & 0.236 \\
Acid & 0.024 & 0.258 & 0.349 & 0.183 & 0.642 \\
Alkali & 0.031 & 0.389 & 0.708 & 0.458 & 0.236 \\
Peroxide & 0.004 & 0.131 & 0.197 & 0.095 & 0.642 \\
\hline
\end{tabular}

ND: not detected 
Table 2. Linearity study for styrene and naphthalene

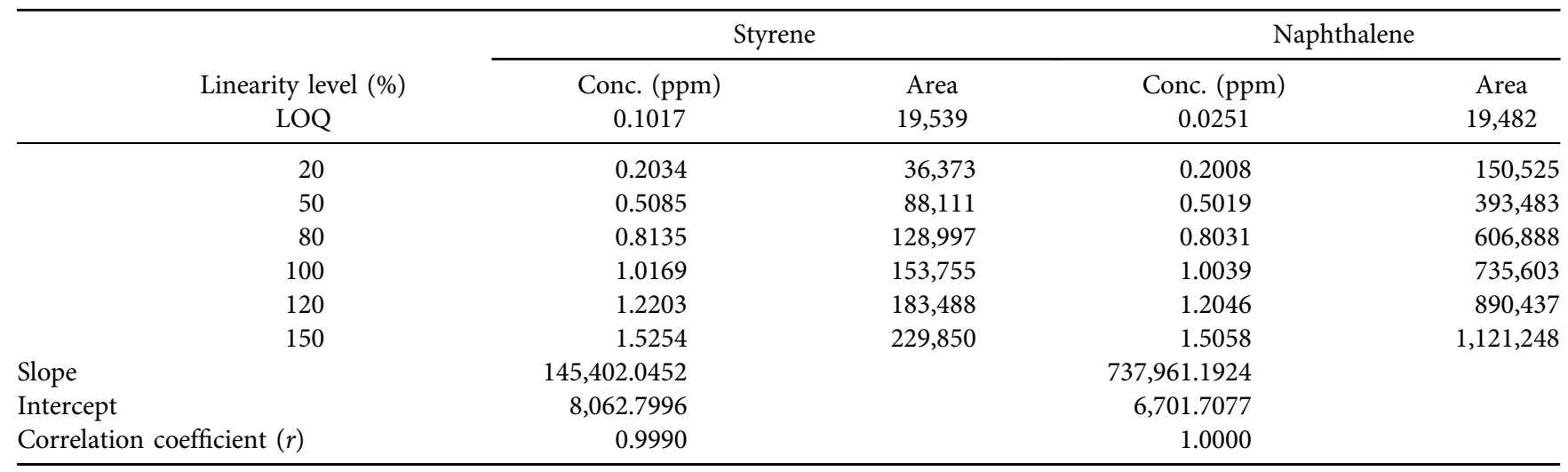

Table 3. Linearity study for divinyl benzene and ethylvinyl benzene isomers

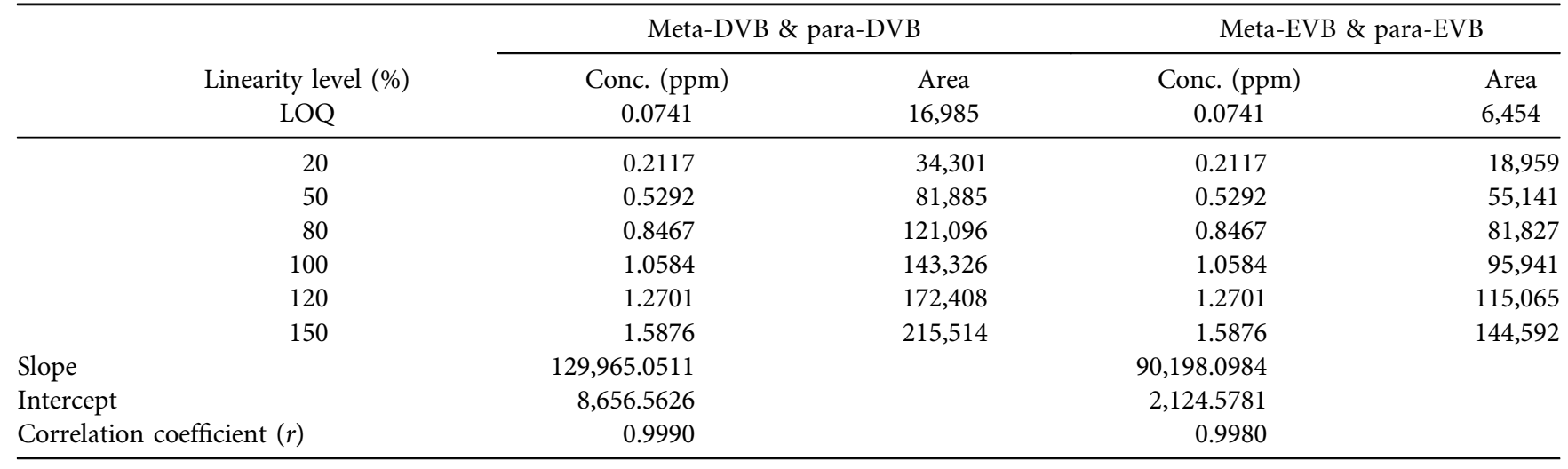

Table 4. Ruggedness study overall precision results

\begin{tabular}{|c|c|c|c|c|c|}
\hline Spiked placebo preparation & & $\begin{array}{l}\text { Styrene } \\
(\mathrm{ppm})\end{array}$ & $\begin{array}{l}\text { Naphthalene } \\
\text { (ppm) }\end{array}$ & $\begin{array}{c}\text { Meta-DVB \& para-DVB } \\
(\mathrm{ppm})\end{array}$ & $\begin{array}{c}\text { Meta-EVB \& para-EVB } \\
(\mathrm{ppm})\end{array}$ \\
\hline \multirow[t]{6}{*}{ Method precision (Analyst-1) } & 1 & 1.202 & 1.089 & 1.092 & 1.093 \\
\hline & 2 & 1.159 & 1.037 & 1.037 & 1.053 \\
\hline & 3 & 1.177 & 1.065 & 1.076 & 1.083 \\
\hline & 4 & 1.239 & 1.057 & 1.052 & 1.060 \\
\hline & 5 & 1.194 & 1.084 & 1.096 & 1.100 \\
\hline & 6 & 1.217 & 1.057 & 1.059 & 1.068 \\
\hline \multirow{6}{*}{$\begin{array}{l}\text { Intermediate precision } \\
\quad(\text { Analyst- })\end{array}$} & 1 & 1.176 & 1.122 & 1.118 & 1.137 \\
\hline & 2 & 1.183 & 1.090 & 1.136 & 1.072 \\
\hline & 3 & 1.183 & 1.124 & 1.116 & 1.141 \\
\hline & 4 & 1.206 & 1.110 & 1.079 & 1.110 \\
\hline & 5 & 1.202 & 1.104 & 1.066 & 1.117 \\
\hline & 6 & 1.196 & 1.145 & 1.176 & 1.148 \\
\hline Average & & 1.194 & 1.085 & 1.084 & 1.094 \\
\hline Standard deviation & & 0.0211 & 0.0323 & 0.0394 & 0.0326 \\
\hline$\%$ RSD & & 1.77 & 2.98 & 3.63 & 2.98 \\
\hline
\end{tabular}

ND: not detected; NA: not applicable

the forced degradation (FD) studies. It may be due to loss of functional group and also due to de-polymerization. The styrene and naphthalene quantity in the product with and without forced degradation was found to be more or less similar. During the linearity study, we found that (Table 2 and Table 3 ) the linearity range of developed method is from LOQ to $150 \%$ of 1 ppm (specification limit) for all the known impurities. The actual range of linearity for styrene is $0.1017-1.5254 \mathrm{ppm}$, naphthalene 0.0251-1.5058 ppm, divinyl benzene 0.0741-1.5876 ppm and for ethylvinyl benzene 0.0741-1.5876 ppm. The LOD, LOQ and linearity graphs are given in Fig. 3[a]-[h].

The developed HPLC method had the capacity to separate the degradation products of both the API and finished 
Table 5. System suitability study parameters

\begin{tabular}{lcccc}
\hline Peak name & Retention time & Theoretical plates & Tailing factor & Resolution \\
\hline Styrene & 12.05 & 168,380 & 1.0 & NA \\
Naphthalene & 15.45 & 814,194 & 1.0 & NA \\
Meta-DVB & 19.59 & 136,724 & 1.0 & 1.1 \\
Para-DVB & 20.62 & 28,293 & 1.54 & 1.70 \\
Meta-EVB & 23.78 & 78,236 & 1.0 & 4.60 \\
Para-EVB & 24.96 & 34,859 & 1.0 & 1.65 \\
\hline
\end{tabular}

Table 6. Marketed sample study data for sodium polystyrene sulfonate

\begin{tabular}{|c|c|c|c|c|c|c|}
\hline $\begin{array}{l}\text { Sodium } \\
\text { polystyrene } \\
\text { sulfonate }\end{array}$ & $\begin{array}{c}\text { Styrene } \\
(\mathrm{ppm})\end{array}$ & $\begin{array}{l}\text { Naphthalene } \\
\text { (ppm) }\end{array}$ & $\begin{array}{c}\text { Meta-DVB \& } \\
\text { para-DVB (ppm) }\end{array}$ & $\begin{array}{c}\text { Meta-EVB \& } \\
\text { para-EVB (ppm) }\end{array}$ & $\begin{array}{c}\text { Individual } \\
\text { unspecified } \\
\text { impurity (ppm) }\end{array}$ & $\begin{array}{c}\text { Total } \\
\text { unspecified } \\
\text { impurity } \\
\text { (ppm) }\end{array}$ \\
\hline $\begin{array}{l}\text { Sava sample Expiry } \\
\text { December } 2020\end{array}$ & 0.128 & 0.020 & ND & ND & ND & ND \\
\hline $\begin{array}{c}\text { Commercial sample } \\
\text { Kayexalate Expiry } \\
\text { September } 2020\end{array}$ & 0.098 & 0.065 & ND & 0.059 & ND & ND \\
\hline
\end{tabular}

Table 7. Marketed sample study data for calcium polystyrene sulfonate

\begin{tabular}{|c|c|c|c|c|c|c|}
\hline $\begin{array}{l}\text { Calcium polystyrene } \\
\text { sulfonate }\end{array}$ & $\begin{array}{l}\text { Styrene } \\
\text { (ppm) }\end{array}$ & $\begin{array}{l}\text { Naphthalene } \\
\text { (ppm) }\end{array}$ & $\begin{array}{c}\text { Meta-DVB \& } \\
\text { para-DVB (ppm) }\end{array}$ & $\begin{array}{c}\text { Meta-EVB \& } \\
\text { para-EVB (ppm) }\end{array}$ & $\begin{array}{c}\text { Individual } \\
\text { unspecified impurity } \\
(\mathrm{ppm})\end{array}$ & $\begin{array}{l}\text { Total unspecified } \\
\text { impurity (ppm) }\end{array}$ \\
\hline $\begin{array}{l}\text { Sava sample expiry } \\
\text { October } 2020\end{array}$ & 0.032 & 0.054 & 0.099 & ND & 0.075 & 0.075 \\
\hline $\begin{array}{l}\text { Commercial sample } \\
\text { Calcium Resonium } \\
\text { expiry July } 2020\end{array}$ & 0.065 & 0.101 & ND & 0.059 & ND & ND \\
\hline
\end{tabular}

product. The precision RSD of each analyte during the ruggedness study was found to be less than 5.0\% (Table 4 ). The mean percentage recoveries $(n=3)$ and $\%$ RSD were calculated. The accuracy of each analyte was $93.0-111.0 \%$ when spiked at LOQ, $50 \%, 100 \%$ and $150 \%$. The system suitability parameters like retention times, peak resolution, theoretical plates and tailing factor of all the known impurities are calculated through the Labsolution software (Table 5). The impurity analysis of marketed samples of both sodium polystyrene sulfonate (Table 6) and calcium polystyrene sulfonate (Table 7) was successfully carried out by this method.

\section{CONCLUSIONS}

In this paper, a systematic quantitative HPLC method of related substances for SPS powder was successfully developed and validated. We have quantitatively analysed all the known organic impurities viz. styrene, naphthalene, divinyl benzene and ethylvinyl benzene from API and finished product samples. The present study provides new information and supporting data for the quality control of commercial samples of both sodium and calcium polystyrene sulfonate powder.

\section{DISCLOSURE STATEMENT}

The authors declare that there are no conflicts of interest.

\section{ACKNOWLEDGEMENTS}

The authors are thankful to Ion Exchange (I) Ltd, Ankleshwar, Gujarat, India for providing the SPS bulk drug with the required known impurities. Thanks are also due to JAMP Corporation, Canada for providing the marketed finished product sample (Kayexalate) for the completion of this work. The authors are also thankful to the Formulation \& Development team, Sava Healthcare Ltd, Pune, India for providing the finished product of SPS and to Mr. Sachin Margaj, Sava Research Centre, Pune for formatting the figures required. 


\section{REFERENCES}

1. Dautzenberg H.; Jaeger W.; Kotz J.; Philipp B.; Seidel C.; Stscherbina D. Polyelectrolytes Formation, Characterization and Applications; Hanser Publishers: Munich, Germany, 1994.

2. Walsh C. P.; Gittes F. R.; Perlmutter D. A.; Stamey A. T. Campbell's Urology, 3; W. B. Saunders: Philadelphia, Pa, USA, 1988; Vol. 5.

3. Asnacios A.; Klitzing R.; Langevin D. Mixed monolayers of polyelectrolytes and surfactants at the air-water interface. Colloids Surf., A 2000, 167, 189-97.

4. Butler J. A. V.; Robins A. B.; Shooter K. V. The viscous behaviour of dilute solutions of a strong polyelectrolyte (Polystyrene Sulphonate). Proc. R. Soc. London A 1957, 214(1226), 299-310.

5. Sedlák M.; Amis E. J. Dynamics of moderately concentrated saltfree polyelectrolyte solutions: molecular weight dependence. $J$. Chem. Phy. 1992, 96, 817-25.

6. Boris D. C.; Colby R. H. Rheology of sulfonated polystyrene solutions. Macromolecules 1998, 31, 5746-55.

7. Cohen J.; Priel Z.; Rabin Y. Viscosity of dilute polyelectrolyte solutions. J. Chem. Phy. 1988, 88, 7111-6.

8. Prini F. R.; Lagos E. A Tracer diffusion, electrical conductivity, and viscosity of aqueous solutions of polystyrene sulfonates. J. of Poly. Sci. A 1964, 26, 2917-28.

9. Rubinstein M.; Colby R. H.; Dobrynin A. V. Dynamics of semi dilute polyelectrolyte solutions. Phy. Rev. Lett. 1994, 73, 2776-9.

10. Vink H. Rheology of dilute polyelectrolyte solutions. Polymer 1992, 33, 3711-6.

11. Ganter J. L. M. S.; Milas M.; Rinaudo M. The viscosity of sodium polystyrene sulphonate, a flexible polyelectrolyte. Polymer 1992, 33, $113-6$

12. Ise $\mathrm{N}$; Okubo $\mathrm{T}$ Mean activity coefficient of polyelectrolytes. V. Measurements of polyvinyl sulfates of various gegenions. J. Phy. Chem. 1967, 71, 1886-90.

13. Ise N.; Okubo T. Mean activity coefficient of polyelectrolytes. VIII. Osmotic and activity coefficients of polystyrene sulfonates of various gegenions. J. of Phy. Chem. 1968, 72, 1361-6.

14. Reddy M.; Marinsky J. A. A further investigation of the osmotic properties of hydrogen and sodium polystyrene sulfonates. J. Phy. Chem. 1970, 74, 3884-91.

15. Chu P.; Marinsky J. A. The osmotic properties of polystyrene sulfonates. I. The osmotic coefficients. J. Phy. Chem. 1967, 71, 4352-9.

16. Okubo T. Surface tension of synthetic polyelectrolyte solutions at the air-water interface. J. Colloid Inter. Sci. 1988, 125, 386-98.
17. Théodoly O.; Ober R.; Williams C. E. Adsorption of hydrophobic polyelectrolytes at the air/water interface: conformational effect and history dependence. Eur. Phy. J. 2001, 5, 51-8.

18. Yim H.; Kent M.; Matheson A.; Ivkov R.; Satija S.; Majewski J.; Smith G.S. Adsorption of poly (styrene sulfonate) to the air surface of water by neutron reflectivity. Macromolecules 2000, 33, 6126-33.

19. Yim H.; Kent M. S.; Matheson A.; Ivkov R.; Satija S.; Majewski J.; Smith G.S.; Stevens M. J. Adsorption of sodium poly(styrene sulfonate) to the air surface of water by neutron and $x$-ray reflectivity and surface tension measurements: polymer concentration dependence. Macromolecules 2002, 35, 9737-47.

20. Agency for toxic substances and disease registry (ATSDR). Toxicological profile of Styrene; U. S. Public Health Service, U.S. Department of Health and Human Services: Atlanta, GA, 1992.

21. Denis H. J; William M; C, Styrene Ullmann's Encyclopedia of Industrial Chemistry, 7th ed.; Wiley, 2007; p 1, doi:10.1002/ 14356007.a25_329.pub2, ISBN 978-3527306732, .

22. MSDS. "Material Safety Data Sheet Styrene (monomer). MSDS". MSDS. Archived from the original on 7 August 2011, 1 November 2010. Retrieved 11 June 2011.

23. US EPA. "OPPT Chemical Fact Sheets (Styrene) Fact Sheet: Support Document (CAS No. 100-42-5)", (December 1994). (PDF). US EPA. Archived (PDF) from the original on 24 December 2010. Retrieved 11 June 2011.

24. U.S. Department of Health and Human Services. Hazardous Substances Data Bank (HSDB, online database). National Toxicology Information Program; National Library of Medicine: Bethesda, MD, 1993.

25. U.S. Department of Health and Human Services. Registry of Toxic Effects of Chemical Substances (RTECS, online database). National Toxicology Information Program; National Library of Medicine: Bethesda, MD, 1993.

26. Coulter K. E.; Kehde, H. Styrene polymers (monomers). In Encyclopaedia of Polymer Science Technology: N. M. Bikales, Eds.; Wiley: New York, 1970; Vol. 13, pp 147-9.

27. Kirk-Othmer Kirk-Othmer Encyclopaedia of Chemical Technology, Third Edition; Wiley: New York, 1981; Vol. 13, pp 685-705.

28. Kirk-Othmer Kirk-Othmer Encyclopaedia of Chemical Technology, Third Edition; Wiley: New York, 1983; Vol. 21, pp 796-9.

29. ICH. Q2 (R1). Validation of Analytical Procedures: Text and Methodology; International Conference on Harmonization: Geneva, 2005. 